\title{
Síndrome de Lemmel: una causa rara de obstrucción biliar no neoplásica de la vía biliar. Presentación de un caso
}

\section{A Case of Lemmel's Syndrome: A Rare Cause of Non-Neoplastic Obstruction of the Biliary Tract}

\author{
Roberto Rodriguez F., MD, ${ }^{1}$ Héctor Polanía L., MD, ${ }^{2}$ Gabriela Evers S., MD. ${ }^{3}$
}

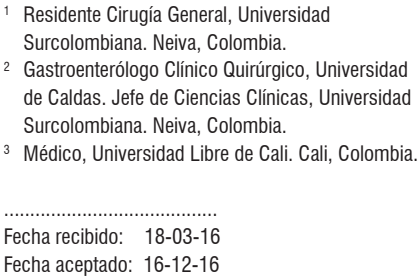

\begin{abstract}
Resumen
Se reporta el caso de una paciente de 77 años de edad con un síndrome ictérico obstructivo, sin presencia de coledocolitiasis u otra alteración del árbol biliar distinta a la presencia de un divertículo duodenal. Se considera que cursa con síndrome de Lemmel, por lo que se realiza manejo endoscópico con esfinterotomía y colocación de stent. El síndrome de Lemmel es una patología poco frecuente que debe tenerse en cuenta como causa de ictericia obstructiva.
\end{abstract}

\section{Palabras clave}

Síndrome de Lemmel, divertículo duodenal, ictericia obstructiva.

\section{Abstract}

We report the case of a 77-year-old woman with jaundice but no evidence of choledocholithiasis or other alterations of the biliary tree except for a duodenal diverticulum. Lemmel's syndrome was diagnosed and an endoscopic sphincterotomy with stenting was performed. Lemmel's syndrome is a rare disease that must be considered as a cause of obstructive jaundice.

\section{Keywords}

Lemmel syndromes, duodenal diverticulum, obstructive jaundice.

\section{INTRODUCCIÓN}

El duodeno corresponde a la segunda localización en donde con más frecuencia se presentan los divertículos gastrointestinales después del colon (1-10). Los divertículos duodenales ocurren frecuentemente entre un $5 \%$ y un $10 \%$ de la población general y su prevalencia se incrementa con la edad, la cual llega hasta un 15\%-20\% a los 80 años de edad; sin embargo, por lo general son hallazgos incidentales, ya que la mayoría son asintomáticos. El $75 \%$ de estos divertículos son periampulares; de estos, los que se localizan a $2-3 \mathrm{~cm}$ por encima de la ampolla de Váter se conocen como divertículos yuxtapapilares (2). Los pacientes rara vez cursan con sínto- mas; sin embargo, estos pueden incluir dolor abdominal, esteatorrea, hemorragia gastrointestinal, perforación, obstrucción intestinal, diverticulitis y patologías de la vía biliar (ictericia obstructiva, colangitis y pancreatitis) (3).

El síndrome de Lemmel, también conocido como ictericia obstructiva intermitente, fue descrito por primera vez en el año de 1934, cuando Lemmel observó que la presencia de divertículos duodenales próximos a la papila de Váter podría favorecer al desarrollo de enfermedades pancreatobiliares. Hasta el momento hay muy pocos casos publicados, por lo que es una patología que no ha sido estudiada a fondo. Se define como una hiperbilirrubinemia a expensas de la bilirrubina directa, secundaria a la relación de un 
divertículo yuxtapapilar con alteraciones del árbol biliar, sin evidencia de coledocolitiasis u otra causa de hiperbilirrubinemia a expensas de directa (4-13). Aunque la coledocolitiasis ocurre comúnmente con una incidencia del $20 \%$ al $40 \%$ en pacientes con divertículos duodenales periampulares, el $41 \%$ de los pacientes que presentan divertículos yuxtapapilares y síntomas secundarios a obstrucción de la vía biliar tiene los conductos biliares y pancreáticos normales en los estudios imagenológicos (2).

En general, la mayoría de los pacientes cursan no solo con ictericia a expensas de la bilirrubina directa, sino también con otros síntomas como dolor abdominal agudo o colangitis. Es característico que los pacientes presenten dolor epigástrico posprandial y sensación de llenura (2). El mecanismo exacto aún no ha sido definido con exactitud; sin embargo, se postula que esté relacionado con el incremento de la presión, la obstrucción mecánica, la distorsión de la porción distal del conducto biliar común y el ducto pancreático o la disfunción o espasmos del esfínter de Oddi. Todo esto favorece el reflujo del contenido duodenal con bacterias intestinales hacia el conducto biliar común y al conducto pancreático y la estasis biliar, lo que finalmente produce los síntomas causados por la patología obstructiva del conducto biliar en su tercio distal intraduodenal (3).

\section{DESCRIPCIÓN DEL CASO}

Paciente femenina de 77 años de edad, ocupación cesante, de procedencia rural. Consulta por cuadro clínico de 1 mes de evolución consistente en dolor a nivel epigástrico irradiado hacia la región lumbar derecha, asociado con sensación de distensión abdominal posprandial. Una semana antes de la consulta refiere ictericia progresiva en mucosa y piel intermitente asociada con episodios febriles no cuantificados. No refiere antecedentes médicos previos. $\mathrm{Al}$ examen físico de ingreso con signos vitales normales, afebril, anictérica, con dolor a la palpación en el epigastrio, sin signos de irritación peritoneal; resto del estudio sin alteraciones. Los estudios paraclínicos iniciales muestran un hemograma con presencia de leucocitosis y neutrofilia, hiperbilirrubinemia directa, con el resto de perfil hepático sin alteración (tabla 1 ).

Se tomó una ultrasonografía hepatobiliar que reportó "vesícula biliar distendida de paredes finas, sin presencia de cálculos en su interior. Colédoco de configuración y diámetro normal”. Dado los hallazgos paraclínicos y ecográficos, se considera que cursa con un cuadro clínico de ictericia con hiperbilirrubinemia a expensas de la directa, por probable proceso obstructivo. Se solicita colangiorresonancia, la cual reportó "distensión de la vesícula biliar sin que se identifiquen imágenes de cálculos en su interior. Dilatación de la vía biliar extrahepática hasta el colédoco distal y leve dilatación del conducto pancreático con aspecto liso de sus contornos. En el nivel inmediato previo a la llegada de estos conductos al duodeno se identifica una formación sacular que se considera corresponde a divertículo duodenal" (figura 1).

Tabla 1. Exámenes de laboratorio

\begin{tabular}{lcc}
\hline \multicolumn{1}{c}{ Estudio } & Rango normal & Resultado \\
\hline Hemoglobina (g/dL) & $13-17$ & 15,2 \\
Hematocrito (\%) & $37 \%-47 \%$ & 45,3 \\
Leucocitos ( $\times 10 \% / \mathrm{L})$ & $4,5-11$ & 13,16 \\
Neutrófilos (\%) & $55-75$ & 86 \\
Eosinófilos (\%) & $1-4$ & 3,4 \\
Basófilos (\%) & $0-2$ & 0,2 \\
Linfocitos (\%) & $35-40$ & 5,6 \\
Monocitos (\%) & $2-8$ & 4,6 \\
Conteo plaquetario (x 10\%/L) & $150-450$ & 217 \\
Bilirrubina total (mg/dL) & $0,3-1,1$ & 3,2 \\
Bilirrubina directa (mg/dL) & $0,0-0,3$ & 2,5 \\
AST (U/L) & $7-41$ & 39 \\
ALT (U/L) & $12-38$ & 56 \\
Fosfatasa alcalina (U/L) & $40-190$ & 124 \\
Tiempo de protrombina & - & $16,9 / 14$ \\
Tiempo de tromboplastina & - & $33,5 / 32$ \\
INR & - & 1,22 \\
\hline
\end{tabular}

ALT: alanina-aminotransferasa; AST: aspartato-aminotransferasa; INR: índice internacional normalizado.

Dada la persistencia de un perfil hepático obstructivo, se decide la realización de una colangiografía retrógrada endoscópica (CPRE) más papilotomía, en la que se encuentra una vía biliar extrahepática de $15 \mathrm{~mm}$ sin defectos de llenado, con abundantes restos alimentarios en la cavidad del divertículo duodenal, que se retira con canastilla de Dormia. Luego se decide la colocación de un stent biliar de $10 \times 10 \mathrm{~mm}$ (figura 2) antes de la papilotomía. Presenta como complicación pancreatitis pos-CPRE. Evoluciona hacia la mejoría, por lo que se ordena el egreso y control para retiro del stent en 10 semanas, procedimiento realizado sin complicaciones.

\section{DISCUSIÓN}

La ictericia obstructiva intermitente por hiperbilirrubinemia directa y que produce síndrome de Lemmel relaciona los divertículos periampulares con alteraciones de la vía biliar, como las litiasis recurrentes, la colangitis o la pancreatitis. El diagnóstico puede ser difícil, pero la sospecha clínica de esta patología, como una posibilidad, en los 

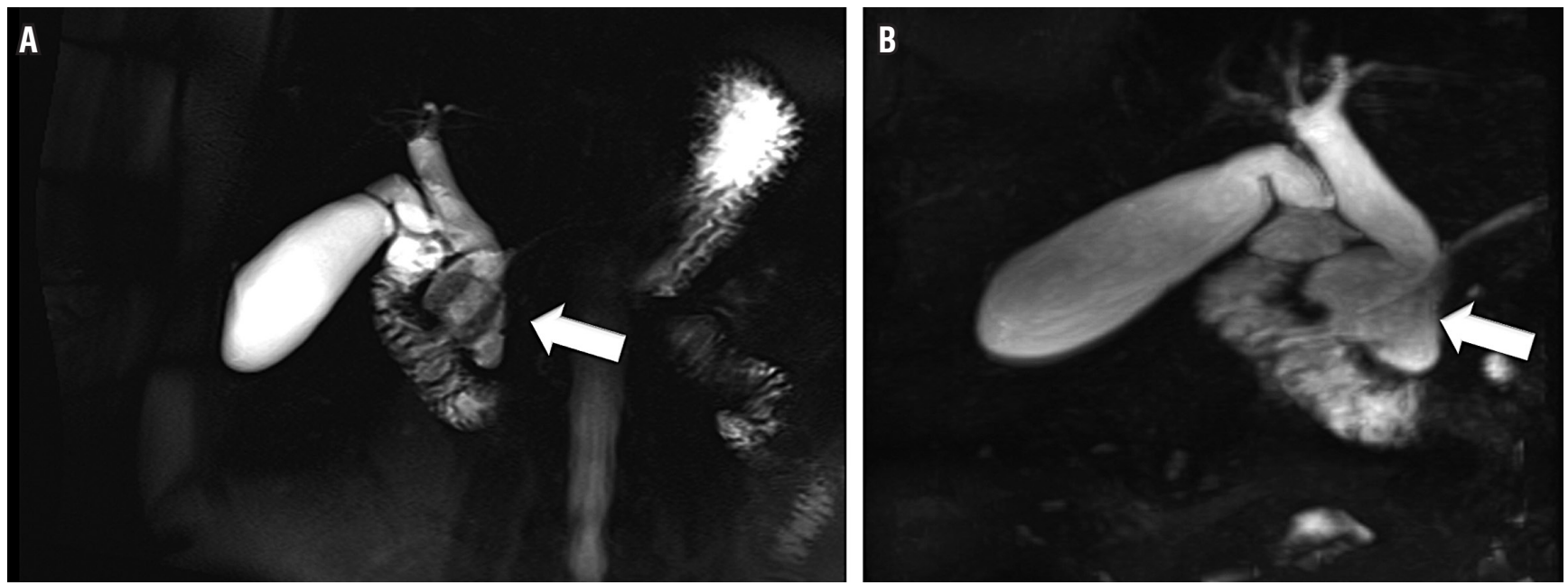

Figura 1. Colangiorresonancia A-B. Se indica la presencia de divertículo duodenal.
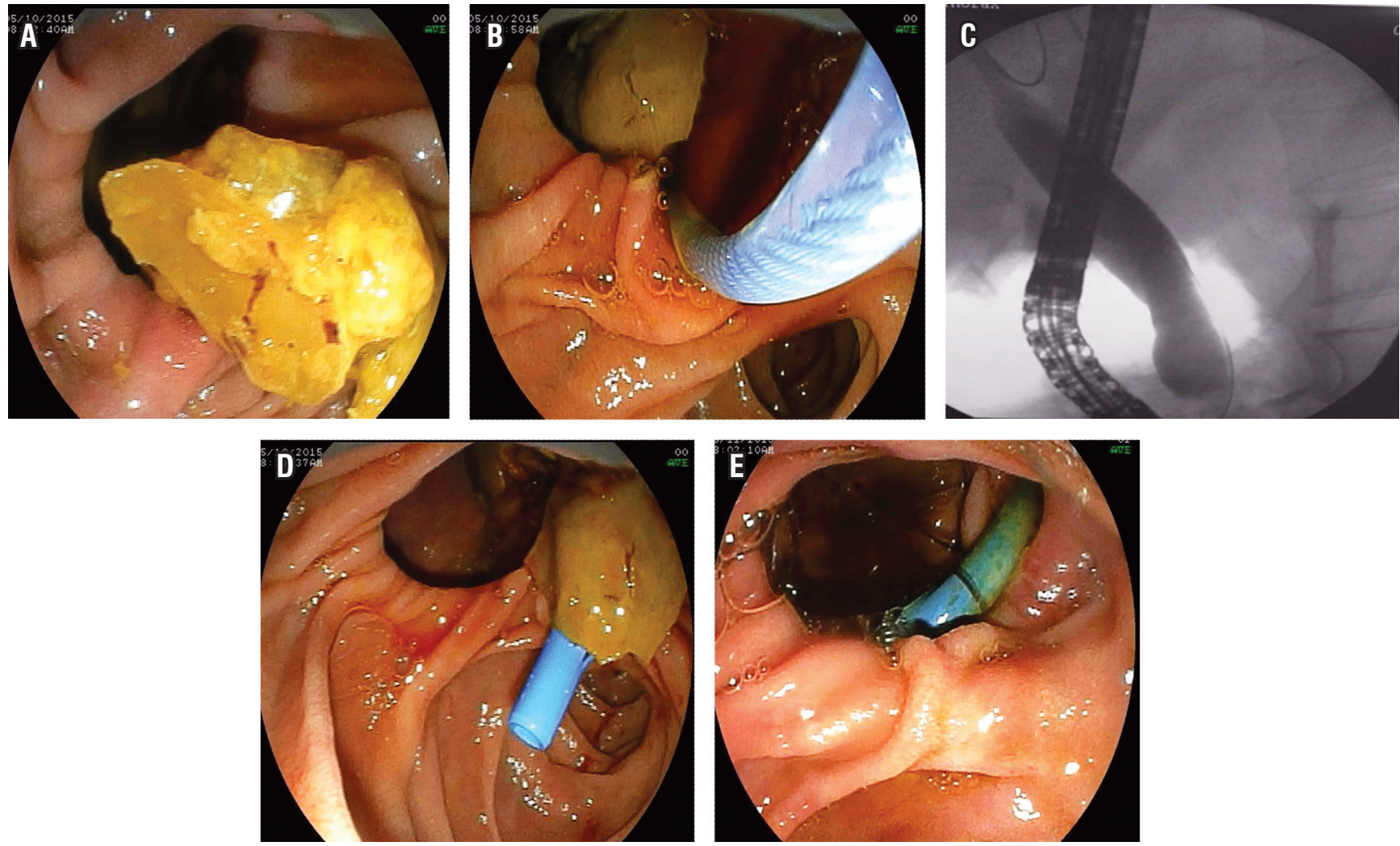

Figura 2. A. Imagen endoscópica del divertículo duodenal. B. Canulación de la papila intradiverticular. C. Colangiografía. D. Stent ulterior a CPRE. E. CPRE de control para el retiro del stent.

pacientes con hiperbilirrubinemia directa sin coledocolitiasis, es de suma importancia para evitar tomar conductas inadecuadas; esta debe iniciarse identificando la presencia del divertículo periampular (5). Se confirma con estudios imagenológicos que incluyen ultrasonografía endoscópica biliopancreática, CPRE, tomografía axial computarizada
(TAC) abdominal o colangiopancreatografía por resonancia magnética (9). Con cualquiera de ellos puede demostrarse la compresión lateral que hay en el conducto biliar común como causa de la presencia del divertículo (4); además se ha reportado que los estudios imagenológicos abdominales de este tipo son una herramienta diagnostica 
útil para identificar patologías duodenales, mejorar las dificultades y aclarar las dudas tanto clínicas como los hallazgos ultrasonográficos (6).

La literatura reporta que la mejor forma de demostrar la presencia de estos divertículos es utilizando la visión lateral endoscópica durante la CPRE. En las tomografías y resonancias en este tipo de divertículos se ven como lesiones cavitadas de la pared fina, que usualmente contienen gas y están situadas en la segunda porción del duodeno. Sin embargo, en ciertos casos estos divertículos periampulares se llenan de líquido y con frecuencia pueden confundirse con pseudoquistes pancreáticos, neoplasias quísticas en la cabeza del páncreas o incluso adenopatías metastásicas; por tanto, no deben utilizarse solamente las imágenes, también debe haber un alto índice de sospecha basado en la historia clínica, los síntomas y los hallazgos paraclínicos para llegar a un correcto diagnóstico en estos pacientes (5).

En el caso que estamos reportando, la clínica y los reportes paraclínicos del perfil hepático indicaron que la paciente cursaba con una ictericia de patrón obstructivo, por hiperbilirrubinemia directa. Por tanto, se procedió a realizar una colangiorresonancia, que describió una formación sacular de contenido líquido con presencia de un nivel líquido-aire en la segunda porción del duodeno en estrecho contacto. Con el nivel de llegada del colédoco con el conducto pancreático, se logró enfocar el caso con una sospecha diagnóstica específica y ulteriormente llevar a cabo el tratamiento indicado. En nuestro caso, se realizó una CPRE que confirmó la presencia del divertículo el diagnóstico de síndrome de Lemmel. Luego se procedió a papilotomía y colocación de stent biliar (14-17).

Actualmente el diagnóstico de este síndrome se realiza, la mayoría de las veces, utilizando la CPRE o la ultrasonografía endoscópica, ya que con ambas se logra confirmar el diagnóstico, excluir otras posibles causas, como coledocolitiasis y tumores, y llevar a cabo la esfinterectomía endoscópica como tratamiento (4).

Generalmente no se recomienda el tratamiento en pacientes asintomáticos. Sin embargo, ya que casi todos los pacientes con este síndrome presentan síntomas relacionados con obstrucción biliar (ictericia, dolor abdominal y colangitis) como resultado de la compresión extrínseca del conducto biliar común, se debe proceder a realizar algún tipo de manejo (5). Los divertículos periampulares sintomáticos pueden ser tratados conservadoramente o endoscópica o quirúrgicamente (8). El objetivo del tratamiento en estos casos es aliviar la obstrucción biliopancreática, ya sea mediante resección quirúrgica o endoscópica del divertículo, esfinterotomía endoscópica, implantando un stent biliar o simplemente removiendo el contenido del divertículo, el cual puede corresponder a un enterolito o a restos de alimento impactado. En la literatura se ha reportado que el tratamiento endoscópico tiene una tasa de éxito alta (6). El tratamiento quirúrgico se reserva para complicaciones severas como perforación o hemorragia importante o en condiciones que cursen con sepsis (6-12), y la CPRE con esfinterotomía es preferible en casos de alteraciones pancreatobiliares (1). Este procedimiento está indicado teniendo en cuenta que no todas las formas del síndrome de Lemmel son causadas por compresión extrínseca (distensión del divertículo periampular) del conducto biliar común; se ha propuesto que la disfunción del esfínter de Oddi o una fibrosis crónica de la papila pueden ser también las causas de esta patología. En estos casos, este sería el procedimiento más sencillo y práctico a realizar para solucionar el problema (5).

Los casos reportados en la literatura son pocos, lo que se traduce en un desconocimiento claro sobre la verdadera incidencia del síndrome de Lemmel. A pesar de lo anterior, su existencia debe tenerse en las opciones diagnósticas en los casos de ictericia obstructiva intermitente. Es necesario el conocimiento de los pocos reportes de casos publicados en la literatura médica, los cuales avalan el adecuado manejo diagnóstico y terapéutico que se dio a nuestro paciente, además de plantear nuevos retos en el abordaje y tratamiento de futuros casos (17).

\section{CONCLUSIÓN}

En la población anciana que muestre un cuadro clínico compatible con ictericia obstructiva en ausencia de litiasis en el conducto biliar común (coledocolitiasis) o en ausencia de una masa tumoral, siempre debe considerarse la posibilidad de que el paciente presente un divertículo periampular causante de la sintomatología. El manejo conservador con estudios imagenológicos siempre debe ser la primera opción para el diagnóstico en estos pacientes, y la intervención quirúrgica o endoscópica deben ser utilizadas con prudencia para realizar un tratamiento seguro y efectivo de este síndrome (7).

\section{REFERENCIAS}

1. Wang Y, Liu K, Yang J. A rare cause of obstructive jaundice. Clin Gastroenterol Hepatol. 2013;11(7):A31.

2. Musumba C, Britton E, Smart H. A man presenting with severe postprandial epigastric pain, jaundice, and pyrexia: more than the usual suspects? Gastroenterology. 2013;144(2):274-469.

3. Gómez Espín R, Sánchez Quiles I, Hallal H, et al. Lesión hepatocelular aguda tras exposición sucesiva a clozapina y olanzapina en un paciente con hepatitis crónica $\mathrm{C}$. Gastroenterol Hepatol. 2010;33(2):150-2. 
4. Rouet J, Gaujoux S, Ronot M, et al. Lemmel's syndrome as a rare cause of obstructive jaundice. Clin Res Hepatol Gastroenterol. 2012;36(6):628-31.

5. Kang HS, Hyun JJ, Kim SY, et al. Lemmel's syndrome, an unusual cause of abdominal pain and jaundice by impacted intradiverticular enterolith: case report. J Korean Med Sci. 2014;29:874-8.

6. Perdikakis E, Chryssou EG, Karantanas A. Diagnosis of periampullary duodenal diverticula: the value of new imaging techniques. Ann Gastroenterol Q Publ Hell Soc Gastroenterol. 2011;24(3):192-9.

7. Karayiannakis AJ, Bolanaki $\mathrm{H}$, Courcoutsakis $\mathrm{N}$, et al. Common bile duct obstruction secondary to a periampullary diverticulum. Case Rep Gastroenterol. 2012;6:523-9.

8. Beisani M, Espin F, Dopazo C, et al. Therapeutic management of juxtapapillary duodenal diverticulum]. Cir Esp. 2013;91(7):463-5.

9. Ono M, Kamisawa T, Tu Y, et al. MRCP and ERCP in Lemmel syndrome. Jop. 2005;6(3):277-8.
10. Oukachbi N, Brouzes S. Management of complicated duodenal diverticula. J Visc Surg. 2013;150(3):173-9.

11. Wiesner W, Beglinger C, Oertli D, et al. Juxtapapillary duodenal diverticula: MDCT findings in 1010 patients and proposal of a new classification. Clin Imaging. 2010;34(2):161.

12. Bittle MM, Gunn ML, Gross J, et al. Imaging of duodenal diverticula and their complications. Curr Probl Diagn Radiol. 2012;41(1):20-9.

13. Alventosa E, Gonzalez CG, Perdomo A, et al. Ictericia obstructiva con nombre propio: síndrome de Lemmel. Objetivos Material y Método; 2012.

14. Fujita N. ERCP for intradiverticular papilla : two- devicesin-one-channel method. 1998;48(5):0-3.

15. Lobo DN, Balfour TW. ERCP for intradiverticular papilla: not the latest trick. Gastrointest Endosc. 1999;50(1):144.

16. Tajima A, Kurata H. Elderly patient with Lemmel syndrome. JSM Gastroenterol Hepatol. 2014;2(1):1010.

17. Rouet J, Gaujoux S, Ronot M, et al. Lemmel's syndrome as a rare cause of obstructive jaundice. Clin Res Hepatol Gastroenterol. 2012;36(6):628-31. 